Review

\title{
Applications of nanomaterials in potentiometric sensors
}

\author{
Tanji Yin ${ }^{\mathrm{a}, \mathrm{b}, \mathrm{c}}$, Wei Qin ${ }^{\mathrm{a}, *}$ \\ ${ }^{a}$ Key Laboratory of Coastal Zone Environmental Processes and Ecological Remediation, Yantai Institute of Coastal Zone Research (YIC), Chinese Academy of Sciences (CAS), \\ Shandong Provincial Key Laboratory of Coastal Zone Environmental Processes, YICCAS, Yantai, Shandong 264003, PR China \\ ${ }^{\mathrm{b}}$ South China Sea Institute of Oceanology, Chinese Academy of Sciences, Guangzhou 510301, PR China \\ ${ }^{\mathrm{C}}$ Graduate School of the Chinese Academy of Sciences, Beijing 100049, PR China
}

\section{A R T I C L E I N F O}

\section{Keywords:}

Aptasensor

Biosensor

Carbon-based nanomaterial

Chemosensor

Ionophore

Ion-selective electrode

Ion-selective microelectrode

Nanomaterial

Neutral species

Potentiometric sensor

\begin{abstract}
A B S T R A C T
Nanomaterials play an important role in the fabrication of chemosensors and biosensors, due to their unique physical and chemical properties, such as large surface area/volume ratio, good conductivity, excellent electrocatalytic activity and high mechanical strength. We review recent advances in the applications of these nanomaterials in potentiometric sensors. We highlight the development of stable solidstate polymeric membrane ion-selective electrodes (ISEs). We describe ISEs based on ionophore-modified nanomaterials. Also, we present highly-sensitive potentiometric biosensors based on nanomaterials.
\end{abstract}

(c) 2013 Elsevier Ltd. All rights reserved.

\section{Contents}

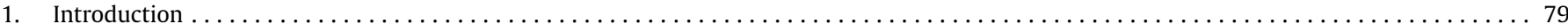

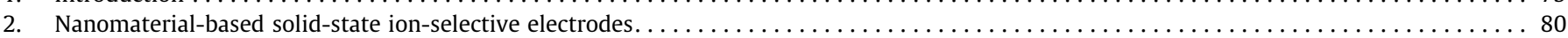

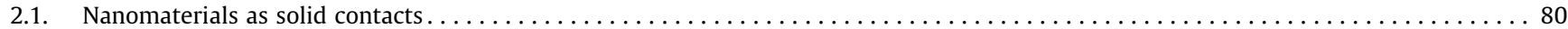

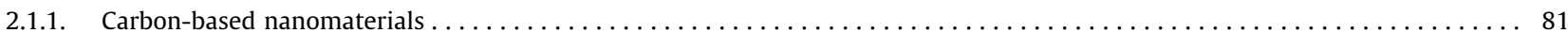

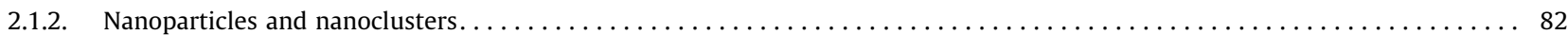

2.2. Nanomaterials directly dispersed in ion-selective membranes $\ldots \ldots \ldots \ldots \ldots$

2.3. Ionophore-modified nanomaterials dispersed in ion-selective membranes $\ldots \ldots \ldots \ldots \ldots$

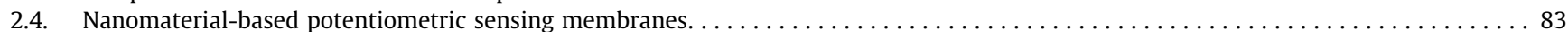

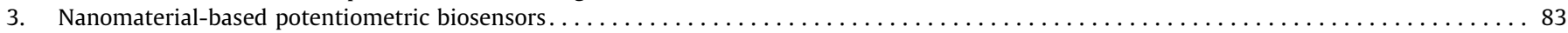

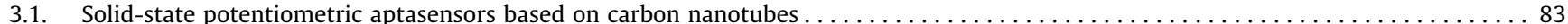

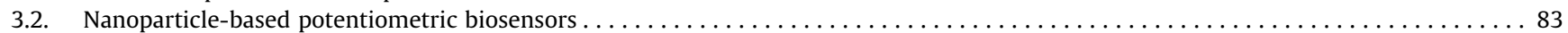

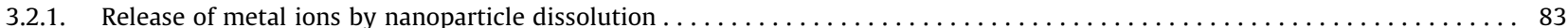

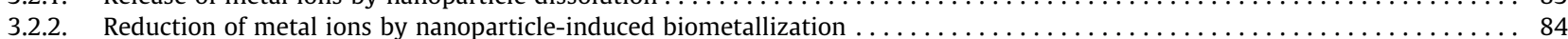

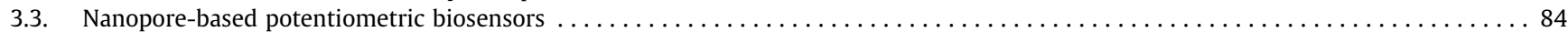

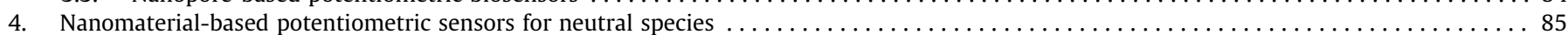

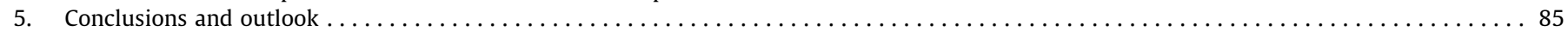

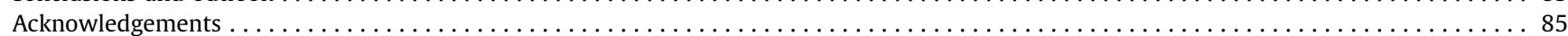

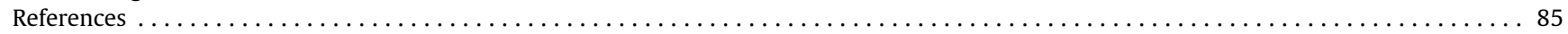

\section{Introduction}

Potentiometric sensors are an important class of electrochemical sensors, which detect the relationship between the activity of

\footnotetext{
* Corresponding author. Tel.: +86 5352109156

E-mail address: wqin@yic.ac.cn (W. Qin).
}

analyte species and the observed potential response with the two-electrode system comprising an indicator electrode and a reference electrode. Ion-selective electrodes (ISEs) with polymeric membranes containing selective carriers (ionophores) are the most commonly-used potentiometric sensors. They have been widely used for directly determining various inorganic and organic ions in medical, environmental and industrial analyses $[1,2]$. Compared 
with other analytical techniques, ISEs have some unique characteristics, such as small size, ease of operation, portability and low cost. In the past few years, ISEs have made great progress in improving the lower limit of detection (LOD), exploiting new membrane materials, proposing new sensing concepts and developing deeper theoretical research about potentiometric responses [2].

Nanomaterials, including nanotubes, nanowires, nanofibers, nanorods, nanoparticles, nanocomposites and other nano-structured materials, have been widely applied to fabricate a variety of chemosensors and biosensors based on their unique physical and chemical properties, such as large surface area/volume ratio, good conductivity, excellent electrocatalytic activity and high mechanical strength [3]. In recent years, nanomaterials were gradually introduced into potentiometric sensors (Fig. 1). For example, the exceptional electrical properties and good hydrophobicities of nanomaterials make them suitable as solid contacts for solid-state ISEs. The immobilization of the ionophore on nanomaterials not only eliminates its leaching from the ion-selective membrane, but also develops an alternative sensing membrane. Also, potentiometric biosensors with new sensing concepts have been developed based on the functionalization of nanomaterials with receptors. The most important contributions of nanomaterials to the field of potentiometry are shown in Table 1.

Based on the significant development of advanced materials, this review summarizes the applications of nanomaterials in potentiometric sensors, including the stable solid-state ISEs based on nanomaterials as solid contacts, ISEs based on ionophore-modified nanomaterials and nanomaterial-based potentiometric biosensors.

\section{Nanomaterial-based solid-state ion-selective electrodes}

\subsection{Nanomaterials as solid contacts}

Solid-contact ISEs are regarded as the most promising generation of potentiometric ion sensors, due to their durability, ease of miniaturization and low maintenance. A solid contact between an electronic conductor and an ion-selective membrane is the essential element for fabricating a stable solid-state polymeric membrane ISE, since its intrinsic property significantly influences the potential stability and reproducibility for long-term use [4]. In the past few decades, various electroactive materials with ionic and electronic conductivities have been extensively investigated as solid contacts in order to obtain stable analytical performance. Conducting polymers, such as polypyrrole (PPy), poly(3-octylthiophene) (POT) and poly(3, 4-ethlyenedioxythiophene) (PEDOT), are commonly used ion-to-electron transducer materials, as reviewed by Bobacka et al. [2,5]. However, these materials suffer from some limitations, such as light sensitivity [6], uptake of POT by the membrane [7], remnants of salt from the polymerization process that

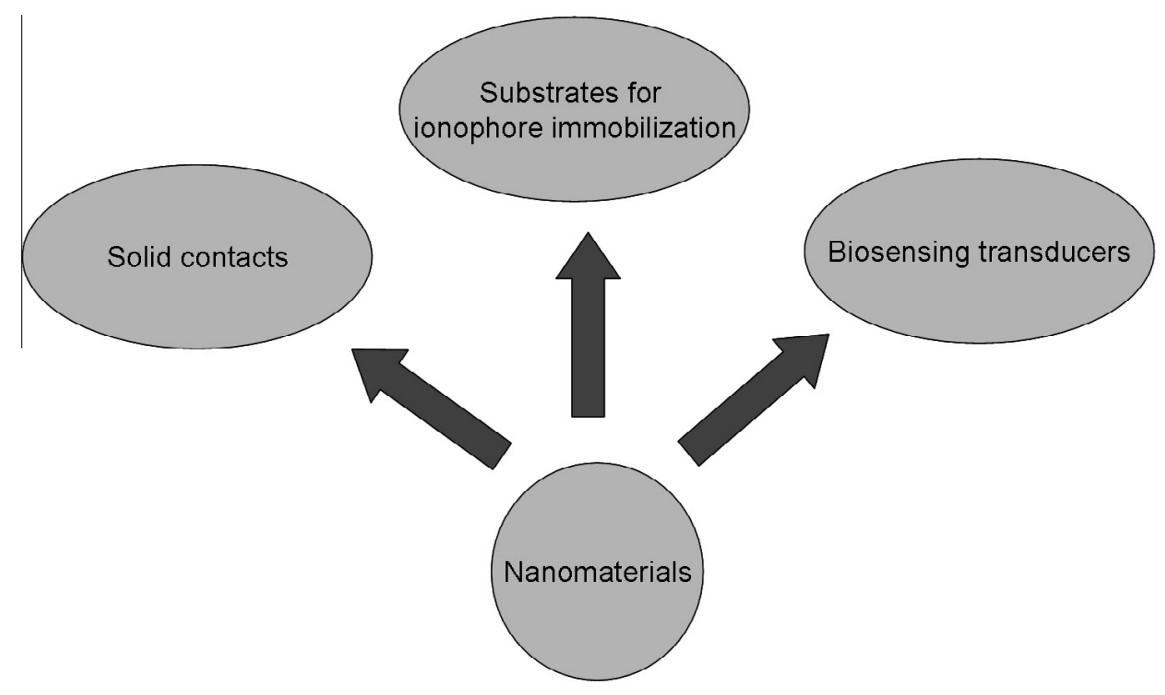

Fig. 1. The most important applications of nanomaterials in potentiometric sensors.

Table 1

Timeline of the most important contributions of nanomaterials to the field of potentiometry

\begin{tabular}{|c|c|c|}
\hline Year & Nanomaterials & Applications \\
\hline 2003 & Biotin-modified gold nanopores & Label-free potentiometric protein sensor \\
\hline 2007 & 3DOM carbon ${ }^{\mathrm{a}}$ & Solid contact \\
\hline 2008 & Carbon nanotubes & Solid contact \\
\hline \multirow[t]{2}{*}{2009} & Polycarbonate nanopore membrane & Ion-channel mimetic sensor for protein detection \\
\hline & Aptamer-modified carbon nanotubes & Potentiometric aptasensor \\
\hline 2010 & Ionophore-modified gold nanoparticles & Ionophore immobilization \\
\hline \multirow[t]{4}{*}{2011} & Gold nanoparticles & Solid contact \\
\hline & Graphene & Solid contact \\
\hline & Ionophore-modified carbon nanotubes & Ionophore immobilization \\
\hline & Ionophore-modified gold nanopores & Solid-state ion-channels \\
\hline \multirow[t]{2}{*}{2012} & Gold nanocluster & Solid contact \\
\hline & Ionophore-modified gold nanoparticles & Potentiometric sensing membrane \\
\hline
\end{tabular}

\footnotetext{
a 3DOM carbon, Three-dimensionally ordered macroporous carbon.
} 
may lead to water uptake [8] and undesired side reactions with redox interferences and sensitivity to dissolved oxygen and $\mathrm{CO}_{2}$ during the ion-to-electron transduction processes [2]. It is therefore necessary to develop alternative solid-contact materials to obtain stable, reliable potential responses.

To develop new electroactive materials as solid contacts, the following prerequisites are required:

(1) reversible transition from ionic to electronic conductivity and sufficiently high bulk (redox) capacitance in order to obtain the potential stability [4];

(2) good hydrophobicity in order to eliminate the undesired water layer between the electronic conductor and the ionselective membrane [9-11]; and,

(3) excellent chemical stability and absence of any side reactions during the process of ion-to-electron transduction [12].

Over the past few years, various nanomaterials, such as carbonbased nanomaterials, Nanoparticles (NPs) and nanoclusters, have been used as solid contacts to develop solid-state ISEs for detection of $\mathrm{K}^{+}, \mathrm{Ca}^{2+}, \mathrm{Ag}^{+}, \mathrm{ClO}_{4}{ }^{-}, \mathrm{pH}$ and choline (Table 2).

\subsubsection{Carbon-based nanomaterials}

Fullerenes are recognized as three-dimensional electron-acceptor materials [13]. They can reversibly accept several electrons and form stable intermediate multi-anions [14]. A self-assembled monolayer (SAM) of the lipophilic and redox-active fullerene derivative was proposed by Pretsch and co-workers [15] to act as a novel solid contact for $\mathrm{K}^{+}$-ISE. They demonstrated that the redox and lipophilic properties of SAM are essential for obtaining a stable potential response and eliminating the aqueous layer between the ion-selective membrane and the underlying contact. However, one limitation of SAM is its inherently low redox capacitance, which is unfavorable for solid-contact ISEs [4]. Solution-cast fullerene- $\mathrm{C}_{60}$ films on carbon substrates have been reported to be efficient charge-transfer mediators [16]. Based on the specific characteris- tics of fullerene- $C_{60}$, Chaniotakis et al. [17] cast a $C_{60}$ film on the glassy-carbon (GC) electrode as an electrochemical mediator of the solid-state $\mathrm{K}^{+}$-ISE. Electrochemical studies based on electrochemical-impedance spectroscopy (EIS) showed that the electrochemically-active layer of the interfacial $C_{60}$ favors efficient ionto-electron transduction between the polymeric ion-selective membrane and the underlying GC electrode, which is essential for obtaining a stable potential response of the solid-state ISE.

Three-dimensionally ordered macroporous (3DOM) carbon, which is fabricated with colloidal crystal templating, was introduced by Bühlmann and Stein et al. [18] to act as a solid contact for the solid-state $\mathrm{K}^{+}$-ISE. The 3DOM carbon-based $\mathrm{K}^{+}$-ISE exhibits an excellent long-term potential stability with a low potential drift of $11.7 \mu \mathrm{Vh}^{-1}$, due to the specific pore and wall structures of 3DOM carbon with a large interfacial area and the high capacitance [19]. Moreover, no significant potential drifts were observed in measuring the effects of $\mathrm{O}_{2}$, light and redox interferences on the potential stability. Also, there is no clear evidence for an aqueous layer forming between the polymeric sensing membrane and the underlying contact, due to the hydrophobic surface of 3DOM carbon. The applications of the 3DOM carbon-based solid-contact ISEs were further investigated [20] and the LODs of $1.6 \times 10^{-7} \mathrm{M}$ and $4.0 \times 10^{-11} \mathrm{M}$ were obtained for $\mathrm{K}^{+}$and $\mathrm{Ag}^{+}$ions, respectively.

Carbon nanotubes (CNTs), including single-walled CNTs (SWCNTs) and multi-walled CNTs (MWCNTs), have unique characteristics, such as large surface area/volume ratio, high chargetransfer capacity, hydrophobicity and chemical stability. These properties are favorable for acting as solid contacts, as demonstrated by Rius and co-workers in developing a series of solid-state ISEs for ions $-\mathrm{K}^{+}[21]$, choline [22], $\mathrm{Ca}^{2+}[23], \mathrm{pH}$ [24] and $\mathrm{ClO}_{4}{ }^{-}$[25]. These ISEs not only are insensitive to light and species displaying redox behaviors, but also show the absence of the aqueous layer between the ion-selective membrane and the electronic conductor. Furthermore, Rius et al. [26] discussed in detail the transduction mechanism of the SWCNT film as a solid contact. They demonstrated that the SWCNT film with small resistance

Table 2

Solid-state polymeric membrane ion-selective electrodes (ISEs) based on nanomaterials as solid contacts

\begin{tabular}{|c|c|c|c|c|c|c|c|c|c|}
\hline \multirow[t]{2}{*}{ Solid contact } & \multirow[t]{2}{*}{ ISM $^{\mathrm{a}}$} & \multirow[t]{2}{*}{ Primary ion } & \multirow[t]{2}{*}{ Potential drift $\left(\mu \mathrm{Vh}^{-1}\right)$} & \multirow[t]{2}{*}{ Aqueous layer } & \multicolumn{4}{|c|}{ Effects of interferents on potential stability } & \multirow[t]{2}{*}{ Ref. } \\
\hline & & & & & $\mathrm{O}_{2}$ & $\mathrm{CO}_{2}$ & Redox & Light & \\
\hline Fullerene- $C_{60}$ & PVC/DOS ${ }^{\mathrm{b}}$ & $\mathrm{K}^{+}$ & - & - & - & - & No & - & [17] \\
\hline 3DOM carbon & $\mathrm{PVC} / 0-\mathrm{NPOE}^{\mathrm{C}}$ & $\mathrm{K}^{+}$ & 11.7 & No & No & Yes & No & No & [18] \\
\hline \multirow[t]{4}{*}{ SWCNTs $^{\mathrm{d}}$} & $\mathrm{MMA} / \mathrm{nBA}^{\mathrm{e}}$ & $\mathrm{K}^{+}$ & & No & No & No & - & - & [21] \\
\hline & & Choline & 224 & No & - & - & - & - & [22] \\
\hline & & $\mathrm{Ca}^{2+}$ & 493 & No & - & - & - & - & [23] \\
\hline & & $\mathrm{pH}$ & 500 & No & - & - & - & - & [24] \\
\hline MWCNT $^{f}$ & $\mathrm{MMA} / \mathrm{nBA}$ & $\mathrm{ClO}_{4}^{-}$ & 220 & No & - & - & - & - & [25] \\
\hline PEDOT(MWCNTs) & PVC/DOS & $\mathrm{K}^{+}$ & - & No & No & No & - & - & [27] \\
\hline $\mathrm{CRGO}^{\mathrm{h}}$ & PVC/o-NPOE & $\mathrm{K}^{+}$ & 12.6 & No & No & No & No & No & [30] \\
\hline Graphene sheets & PVC/DOS & $\mathrm{K}^{+}$ & - & No & & Yes & - & - & [31] \\
\hline ERGO $^{\mathrm{i}}$ & PVC/o-NPOE & $\mathrm{Ca}^{2+}$ & 14.7 & No & No & No & No & No & [32] \\
\hline Carbon black & PVC/o-NPOE & $\mathrm{K}^{+}$ & 15.1 & No & No & No & No & No & [33] \\
\hline PANI-NP $/ \mathrm{K}^{+}-$ISM & PVC/DOS & $\mathrm{K}^{+}$ & - & - & - & - & - & - & [35] \\
\hline PANI-NP & $\mathrm{SR}^{\mathrm{k}} / \mathrm{DOS}$ & $\mathrm{Ca}^{2+} / \mathrm{Ag}^{+}$ & - & No & No & - & - & No & [36] \\
\hline Au@C4/C8 ${ }^{1}$ & PVC/DOS & $\mathrm{K}^{+}$ & $380 / 660$ & No & - & - & - & - & [38] \\
\hline $\mathrm{MPCs}^{\mathrm{m}}$ & PVC/DOS & $\mathrm{K}^{+}$ & 10.1 & No & No & No & No & No & [41] \\
\hline
\end{tabular}

a ISM, Ion-selective membrane.

b DOS, bis(2-ethylhexyl) sebacate.

c $o$-NPOE, $o$-nitrophenyl octyl ether.

d SWCNTs, Single-walled carbon nanotubes.

e MMA/nBA, Methyl methacrylate/ $\eta$-butylacrylate.

${ }^{f}$ MWCNTs, Multi-walled carbon nanotubes.

g PEDOT(MWCNTs), Poly(3,4-ethylenedioxythiophene) doped with multi-walled carbon nanotubes.

h CRGO, Chemically-reduced graphene oxide.

i ERGO, Electrochemically-reduced graphene oxide.

j PANI-NPs, Polyaniline nanoparticles.

k SR, Silicone rubber.

${ }^{1}$ Au@C4/C8, Gold nanoparticles modified with butylthiol/octanethiol.

m MPCs, Monolayer-protected Au clusters. No, Absence/ Insensitive; Yes, sensitive. 
and large bulk capacitance is an asymmetric capacitor where one side is formed by electrons (holes) in the walls of the SWCNTs and the other side is formed by cations (anions) in the ion-selective membrane, when acting as an ion-to-electron transducer. Also, Ivaska et al. [27] electrochemically synthesized poly(3,4-ethylenedioxythiophene) (PEDOT) doped with carboxyl-functionalized MWCNTs [PEDOT(MWCNT)] as an ion-to-electron transducer of the solid-contact $\mathrm{K}^{+}$-ISE. The experimental results from cyclic voltammetry (CV) and EIS show that the electroactive film, PEDOT(MWCNT), has the capability to act as a solid contact, due to its high redox capacitance. However, the incorporation of PEDOT may bring back the inherent problems of conducting polymerbased solid contact.

Interestingly, SWCNTs are also employed as an effective transducer layer for fabricating reliable, stable solid-state reference electrodes (SSREs), due to their hydrophobicity and UV/Vis light insensitivity $[28,29]$. For example, Riu et al. [28] fabricated a series of SSREs using SWCNTs as efficient ion-to-electron transducers and polyacrylic polymers as the reference membranes containing the $\mathrm{Ag} / \mathrm{AgCl} / \mathrm{Cl}^{-}$ion system. They investigated photo-polymerized and thermo-polymerized polyacrylic polymers as the $\mathrm{Ag} / \mathrm{AgCl} / \mathrm{Cl}^{-}$ ion-system reservoirs for the SWCNT-based SSREs. The photopolymerized poly( $n$-butylacrylate) membrane solid-state reference electrode showed better results, including satisfactory mediumterm stability in $0.01 \mathrm{M} \mathrm{KCl}(-1.1 \pm 0.2 \mathrm{mV} / \mathrm{h})$ and insensitivity to $\mathrm{pH}$, room light and various salts.

The same group [29] prepared octadecylamide-functionalized SWCNTs (SWCNTs-ODA) as the transducer layer to fabricate a disposable screen-printed solid-state reference electrode. The proposed reference electrode not only is insensitive to various ions, small charged molecules, proteins, $\mathrm{pH}$, redox species and ambient light, but also shows a medium-term potentiometric stability $\left(-0.9 \pm 0.2 \mathrm{mV} \mathrm{h}^{-1}\right)$ in $10^{-3} \mathrm{M} \mathrm{KCl}$ and a long shelf life ( 8 months).

Graphene, as a two-dimensional carbon nanomaterial, has similar characteristics to CNTs, such as large specific surface area, fast electron-transfer capability, excellent conductivity and electrocatalytical activity. It has been used as a solid contact to develop solidstate ISEs. For example, the chemically-reduced graphene oxide (CRGO) was proposed by Wu et al. [30] as a solid-contact layer of the solid-state $\mathrm{K}^{+}$-ISE. The CRGO-based electrodes show excellent potentiometric behaviors, such as potential stability, fast response time, and insensitivity to $\mathrm{O}_{2}, \mathrm{CO}_{2}$, light and redox interferences. Similarly, graphene sheets were used by Zhang and Niu et al. [31] as a transducer layer to fabricate the solid-contact $\mathrm{K}^{+}$-ISE. However, the CRGO film as solid contact is usually fabricated by the multi-step drop-casting method, which is time consuming and complicated. A simple, rapid, efficient one-step electrodeposited technique was subsequently proposed by $\mathrm{Wu}$ et al. [32] to prepare GO film as an ion-to-electron transducer for the screenprinted $\mathrm{Ca}^{2+}$-ISE.

Carbon black (CB), as a form of amorphous carbon, shows advantages of low production cost, large surface area, high conductivity and hydrophobicity. These properties are favorable in acting as a solid contact for the solid-state $\mathrm{K}^{+}$-ISE, as demonstrated by Paczosa-Bator [33].

\subsubsection{Nanoparticles and nanoclusters}

Polyaniline (PANI) has been extensively studied for numerous practical applications, due to its excellent electrical properties, good environmental stability and processability. PANI contains three kinds of oxidation state, which depend on the $\mathrm{pH}$ of sample solution [34]. Among them, the electrically-conducting emeraldine salt (ES) form is regarded as the most useful, stable form of PANI. The membrane with the pure PANI NPs, mainly in the ES form, was found to display an exceptionally good $\mathrm{pH}$ stability [35]. Lindfors et al. [35] prepared the homogenous mixture of PANI
NPs and plasticized PVC membrane as an internal ion-to-electron transducer of the solid-contact $\mathrm{K}^{+}$-ISE. The geometrically welldefined internal solid contact with good mechanical strength is favorable for improving the reproducibility of the solid-contact ISEs. Additionally, Lindfors and Gyurcsányi et al. [36] used PANI NPs as a solid contact to develop silicone rubber (SR)-based $\mathrm{Ca}^{2+}$ ISEs and $\mathrm{Ag}^{+}$-ISEs. The impedance of the proposed solid-contact ISEs was found to be lowered, which is due to the presence of PANI NPs between the ion-selective membrane and the underlying electronic conductor.

Gold NPs (AuNPs) with excellent physical and chemical characteristic have been extensively used to fabricate various chemical and biological sensors [37]. Michalska et al. introduced AuNPs to act as a solid contact for the solid-state $\mathrm{K}^{+}$-ISE [38]. To increase the lipophilicity, AuNPs were modified with aliphatic thiols using the Brust-Schiffrin method in a two-phase liquid-liquid system $[39,40]$. The proposed electrode shows a highly stable potential response, due to the high capacitance and lipophilicity of the aliphatic thiol-modified AuNPs.

Monolayer-protected Au clusters (MPCs) doped with tetrakis (4-chlorophenyl) borate were prepared by Niu et al. [41]. They demonstrated that the new material has the unique properties to act as an effective solid contact of the solid-state $\mathrm{K}^{+}$-ISE, such as high redox capacitance, sufficient ion-exchange property, good long-term chemical stability, low electrical resistance, excellent hydrophobicity and insensitivity to $\mathrm{O}_{2}, \mathrm{CO}_{2}$, light and redox interferents.

\subsection{Nanomaterials directly dispersed in ion-selective membranes}

Nanomaterials can be directly dispersed in the ion-selective membrane to fabricate all-solid-state ISEs. However, the dispersion of nanomaterials in the ion-selective membrane is critical for forming the homogeneous sensing membrane. For example, Abbaspour et al. [42] dispersed MWCNTs in PVC-based ion-selective membrane with the ultrasonic technique to develop a $\mathrm{Cr}^{3+}$-ISE. Bobacka et al. [43] mixed MWCNTs or poly(3-octylthiophene) (POT) with the $\mathrm{K}^{+}$-ion-selective membrane components to develop all-solidstate $\mathrm{K}^{+}$-ISEs. By comparison, they demonstrated that MWCNTs are more suitable to act as an ion-to-electron transducer than POT, due to their high electronic conductivity and large redox capacitance [43]. Moreover, the selectivities of the proposed electrodes were found to be insignificantly influenced by the amount of MWCNTs or POT in the ion-selective membrane. Qin et al. [44] found that MWCNTs can be well dispersed in ion-selective membranes with poly(ethylene oxide) (PEO)-poly(propylene oxide) (PPO)-poly(ethylene oxide) block copolymers (PEO-PPO-PEO, Pluronic F127) as dispersant. They used the MWCNTs/F127-based ion-selective membranes with different ionophores to develop all-solid-state $\mathrm{K}^{+}, \mathrm{Na}^{+}, \mathrm{Ca}^{2+}$-ISEs and $\mathrm{Cu}^{2+}$-ISEs [44,45]. The proposed electrodes display similar selectivities to those of the corresponding liquid-contact PVC-based ISEs.

The plasticizer-free polyacrylate-based polymer membranes with low diffusion coefficients are regarded as an alternative membrane material for fabricating ISEs [46]. However, the high electrical resistance of polyacrylate membranes significantly limits their applications. Platinum NPs (PtNPs) were incorporated by Michalska et al. [47] into the photopolymerized poly(n-butyl acrylate)-based ion-selective membrane for lowering the electrical resistance. Interestingly, the potential stability of the proposed polyacrylate-based electrode was found to be improved, because PtNPs facilitate ion-to-electron transduction between the solid contact (POT) and the ion-selective membrane. However, the presence of PtNPs in the ion-selective membrane may lead to serious oxygen interference. 
2.3. Ionophore-modified nanomaterials dispersed in ion-selective membranes

The immobilization of the ionophore in the polymeric membrane matrix offers a robust approach to eliminate leaching of the ionophore from the ion-selective membrane to the sample solution, which is requisite to fabricate the ISE with a long operating lifetime. For example, Gyurcsányi et al. [48] fabricated ionophore-AuNP conjugates based on the self-assembly of the $\mathrm{Ag}^{+}$-selective ligand onto the surface of AuNPs. The conjugates were incorporated into the ion-selective membrane to develop the $\mathrm{Ag}^{+}$-ISEs with nanomolar LODs. The methodology with ionophore immobilized on AuNPs can effectively lower the mobility of ionophore in the membrane phase and eliminate the light sensitivity of the sensing membrane.

Blondeau et al. [49] synthesized a hybrid material with benzo18-crown-6 (lead ionophore) covalently immobilized onto MWCNTs to develop potentiometric $\mathrm{Pb}^{2+}$ sensors. The hybrid material acts as not only a recognition receptor, but also an ionto-electron transducer of the solid-state $\mathrm{Pb}^{2+}$-ISE. The proposed sensors show excellent intermediate-term potential stability without leaching out of the ionophore from the ion-selective membrane. Also, the selectivity of the electrodes was dramatically improved, because the specific structure of the hybrid material favors the formation of sandwich complexes between the $\mathrm{Pb}^{2+}$ ion and the two ionophore molecules.

\subsection{Nanomaterial-based potentiometric sensing membranes}

Conventional polymeric membrane ISEs suffer from some limitations, such as leaching of the membrane components into the sample solution and extraction of lipophilic molecules into the polymeric membrane. Moreover, they cannot be applied in nonaqueous solutions. Consequently, some nanomaterial-based potentiometric ion sensors have been developed without polymeric membranes matrix. For example, gold nanopores, which are fabricated by electroless deposition of gold onto the surface of track-etched polycarbonate nanopore membranes, are used to immobilize $\mathrm{Ag}^{+}$-selective ionophore to develop solid-state ion channels for potentiometric sensing [50]. The nanopore-based $\mathrm{Ag}^{+}$-ISE shows fast Nernstian potential responses with the LOD in the sub-nM range. Moreover, the proposed electrode displays extraordinary ion-recognition selectivities.

Michalska et al. [51] synthesized dithizone-decorated AuNPs to act as an alternative potentiometric sensing membrane for the $\mathrm{Cu}^{2+}$ ion. The membrane shows Nernstian potentiometric responses in the absence of a polymeric membrane matrix, due to the interaction between $\mathrm{Cu}^{2+}$ ions and the ligand immobilized on the AuNP layer. Moreover, the proposed membrane shows selectivity superior to the PVC-based $\mathrm{Cu}^{2+}$ polymeric membrane, due to not only the intrinsic properties of the applied ligand, but also the stable conformation of the complex on the surface of AuNPs.

\section{Nanomaterial-based potentiometric biosensors}

\subsection{Solid-state potentiometric aptasensors based on carbon nanotubes}

Based on $\pi-\pi$ stacking interactions between the nucleic-acid bases and the CNT walls [52], CNTs are used as transduction elements to develop solid-state potentiometric aptasensors. These aptasensors represent a promising research area, in which the polymeric membranes are replaced by nanomaterials. The sensing mechanism is quite different from the well-established phase- boundary potential model for the traditional polymeric membrane ISES.

Rius et al. [53] covalently immobilized the $5^{\prime}-\mathrm{NH}_{2}$-functionalized 15-mer thrombin-binding aptamer (TBA) on the carboxylated SWCNTs using the carbodiimide-mediated wet-chemistry method [54] to develop a solid-state potentiometric aptasensor for detecting thrombin. The aptasensor displays a direct potentiometric response to thrombin in concentration range $10^{-7}-10^{-6} \mathrm{M}$ with the sensitivity of $8.0 \mathrm{mV} / \log \mathrm{a}_{\text {thrombin }}$ and the LOD of $80 \mathrm{nM}$. The biosensing mechanism is based on competitive binding between thrombin and SWCNTs for TBA. That is, in the absence of thrombin, TBA is self-assembled on CNTs by $\pi-\pi$ stacking interactions between the aptamer bases and SWCNT walls; however, in the presence of thrombin, the affinity interaction between TBA and thrombin induces a conformational change in the aptamer, which separates the phosphate negative charges of TBA from the SWCNT sidewalls and subsequently leads to a potential change.

Similarly, pathogens, such as Salmonella typhi (S. typhi) [55], Escherichia coli (E. coli) [56] and Staphylococcus aureus (S. aureus) [57], have been detected based on potentiometric aptasensors using CNTs as transducers and proper aptamers as recognition elements. These sensors offer a simple, selective method for detecting and identifying pathogens. However, the low sensitivities $(<2 \mathrm{mV} /$ decade), the narrow response ranges and the rigorous experiment conditions, such as the constant ionic strength of the sample solution and the elimination of the other charged species that would interfere with the potential change, would limit their real-world applications.

\subsection{Nanoparticle-based potentiometric biosensors}

Based on their unique optical and electrochemical properties, NPs, such as metal NPs (gold, silver) or semiconductor dots, have been extensively applied in biosensing [58]. The applications of NPs as labels in biosensors represent an interesting field of research and applications. The pioneering work was done by Mirkin and Letsinger et al. [59], who developed a scanometric DNA-arraydetection system based on oligonucleotide targets labeled with AuNPs. Afterwards, Wang et al. [60-62] used AuNPs or silver-enhanced colloidal gold as labels for electrochemical detection of DNA hybridization. These NP-based electrochemical biosensors typically employ the stripping voltammetric technique as the read-out principle due to the "built-in" preconcentration step that obtains ultratrace-level LODs.

Potentiometric ISEs are recognized as an attractive tool for determining trace metals in confined samples, because the potential signal or LOD is independent of the sample volume and electrode surface. Miniaturized ISEs have been reported to detect femtomole amounts of ions in microvolume samples [63,64], so ISEs/ion-selective microelectrodes (ISEs/IS $\mu$ Es) based on NPs have been employed for highly-sensitive bioassays (Table 3 ).

\subsubsection{Release of metal ions by nanoparticle dissolution}

Fig. 2 shows potentiometric biosensors using NPs as labels. The sensing mechanism is based on a sandwich assay, where the target is first captured by the immobilized primary receptor and then attached to the NP-labeled secondary receptor. Potentiometry is finally used to detect the dissolution products of NPs after a release step with $\mathrm{H}_{2} \mathrm{O}_{2}$.

In the past few years, several kinds of NPs have been used as labels to develop highly-sensitive potentiometric biosensors using ISEs/IS $\mu$ Es for signal transduction. For example, Bakker and coworkers [65] developed a potentiometric IgG immunosensor based on silver-enlarged AuNP labels. A silver IS $\mu \mathrm{E}\left(\mathrm{Ag}^{+}-\mathrm{IS} \mu \mathrm{E}\right)$ was used to detect the released silver ion with $\mathrm{H}_{2} \mathrm{O}_{2}$. The proposed immunosensor offers a promising method for highly-sensitive bioaffinity 
Table 3

Nanoparticle-based potentiometric biosensors using ion-selective electrodes/microelectrodes (ISEs/IS $\mu$ Es) for signal transduction

\begin{tabular}{|c|c|c|c|c|c|}
\hline Nanoparticles (NPs) & Target & Signal transduction & Linear range & LOD & Ref. \\
\hline Silver-enhanced AuNPs & $\operatorname{IgG}$ & $\mathrm{Ag}^{+}-\mathrm{IS} \mu \mathrm{E}$ & $0.5-7.5 \mu \mathrm{g} \mathrm{mL}^{-1}$ & $12.5 \mathrm{pmol} / 50 \mu \mathrm{L}$ & [65] \\
\hline CdS quantum dots & DNA & $\mathrm{Cd}^{2+}-\mathrm{IS} \mu \mathrm{E}$ & $0.01-300 \mathrm{nM}$ & $2 \mathrm{fmol} / 200 \mu \mathrm{L}$ & [66] \\
\hline CdS quantum dots & Thrombin & $\mathrm{Cd}^{2+}-\mathrm{IS} \mu \mathrm{E}$ & $10-250 \mu \mathrm{g} \mathrm{mL}^{-1}$ & $28 \mathrm{fmol} / 200 \mu \mathrm{L}$ & [67] \\
\hline CdSe quantum dots & $\operatorname{IgG}$ & $\mathrm{Cd}^{2+}-\mathrm{IS} \mu \mathrm{E}$ & $0.15-4.0 \mathrm{pmol} / 150 \mu \mathrm{L}$ & $<10 \mathrm{fmol} / 150 \mu \mathrm{L}$ & [68] \\
\hline AgNPs & Glucose & $\mathrm{Ag}^{+}-\mathrm{ISE}$ & $0.1-3 \mathrm{mM}$ & $1.0 \times 10^{-5} \mathrm{M}$ & [69] \\
\hline AuNPs & NADH & $\mathrm{Cu}^{2+}-\mathrm{ISE}$ & $1 \times 10^{-5}-1 \times 10^{-2} \mathrm{M}$ & - & [71] \\
\hline AuNPs & DNA & $\mathrm{Ag}^{+}-\mathrm{IS} \mu \mathrm{E}$ & $100 \mathrm{fM}-10 \mathrm{nM}$ & $0.2 \mathrm{amol} / 4 \mu \mathrm{L}$ & [72] \\
\hline
\end{tabular}
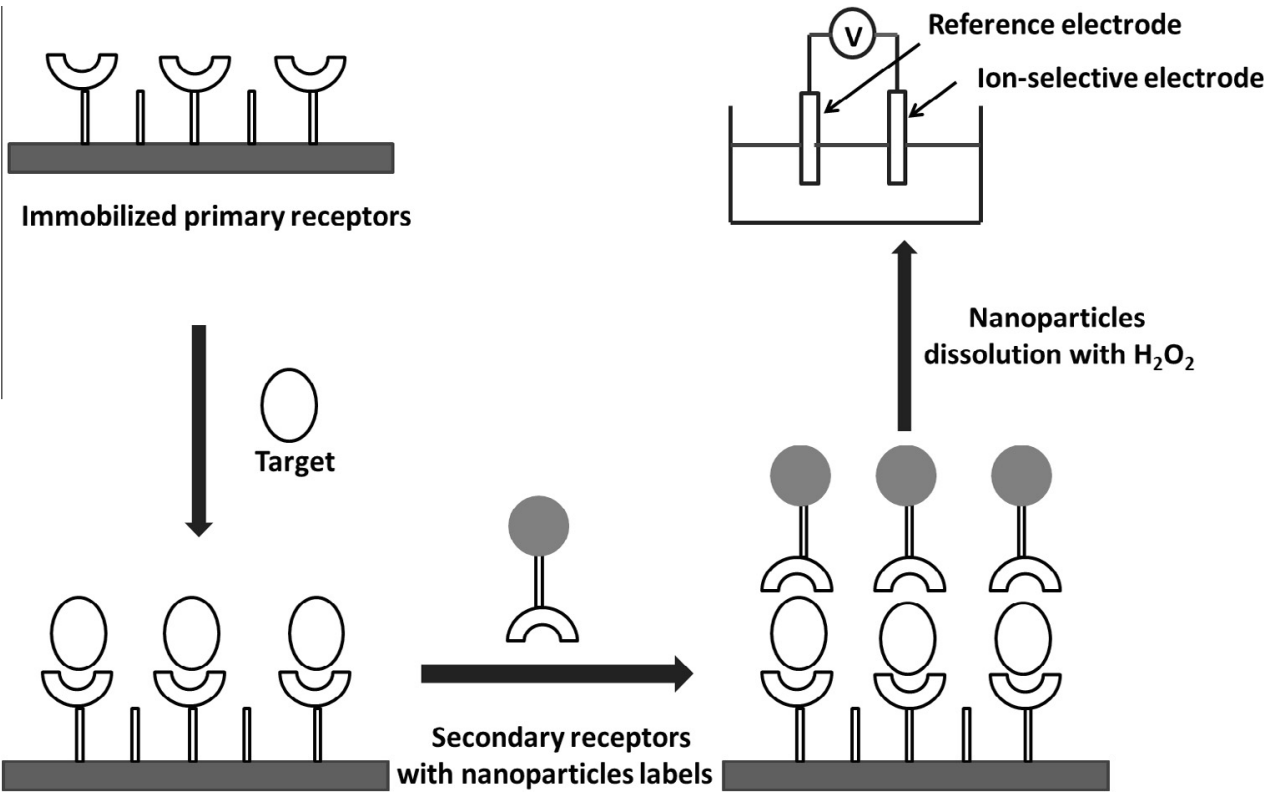

Fig. 2. Potentiometric biosensors using nanoparticles as labels.

assay, with an LOD of around $12.5 \mathrm{pmol}$ of IgG in the $50-\mu \mathrm{L}$ sample solution. The same group [66] developed a potentiometric microsensor for detection of DNA hybridization based on CdS quantum dots (QDs) labeled on a secondary oligonucleotide. After the sandwich DNA hybridization, the captured CdS QDs were dissolved in $\mathrm{H}_{2} \mathrm{O}_{2}$ and the released $\mathrm{Cd}^{2+}$ ions were measured by a $\mathrm{Cd}^{2+}-\mathrm{IS} \mu \mathrm{E}$. The potentiometric immunosensor exhibited a wide linear response range of $0.01-300 \mathrm{nM}$ of the target DNA, with a low LOD of $2 \mathrm{fmol}$ in 200- $\mu \mathrm{L}$ sample solution. CdS QDs were also used as labels to develop an aptamer-based potentiometric biosensor [67]. Also, a potentiometric immunoassay based on CdSe QDs as labels was developed by Pretsch and co-workers [68] and the LOD of $<10 \mathrm{fmol}$ IgG in $150-\mu \mathrm{L}$ sample solution was obtained.

Silver NPs (AgNPs) were also used as a potentiometric redox marker to develop a potentiometric glucose biosensor [69]. The product, $\mathrm{H}_{2} \mathrm{O}_{2}$, generated by the enzyme-substrate reaction between glucose and glucose oxidase, is used to oxidize AgNPs to free $\mathrm{Ag}^{+}$ions, which are related to the concentration of glucose and can be detected by an $\mathrm{Ag}^{+}$-ISE. The proposed sensor shows good repeatability and high reproducibility for detection of glucose with an LOD of $1.0 \times 10^{-5} \mathrm{M}$.

\subsubsection{Reduction of metal ions by nanoparticle-induced} biometallization

Due to their intrinsic properties, metal NPs can also be applied to catalyze the reduction of metal ion by an enzymatically-generated reducing agent [70]. Such biometallization processes can be monitored by ISEs in real time. For example, a potentiometric NADH biosensor was successfully proposed by Wang et al. [71] based on monitoring the NADH-stimulated catalytic reduction of $\mathrm{Cu}^{2+}$ in the presence of AuNPs with a $\mathrm{Cu}^{2+}$-ISE. The presence of the AuNPs in the enzyme-mediated reduction of metal ions was found to be crucial in improving the sensitivity.

Wang et al. [72] reported a highly-sensitive potentiometric biosensor for detecting DNA hybridization based on monitoring the depletion of $\mathrm{Ag}^{+}$ions in the presence of AuNPs induced by the biocatalytic reaction of alkaline phosphate (ALP)-enzyme labels with a solid-contact $\mathrm{Ag}^{+}$-IS $\mu \mathrm{E}$. The proposed method does not need to dissolve the nanocrystal tracer with $\mathrm{H}_{2} \mathrm{O}_{2}$ or to have a preconcentration step. The sensor has been used to detect DNA and 16S rRNA of E. coli pathogenic bacteria with LODs of $50 \mathrm{fM}$ and $10 \mathrm{CFU}$ in $4-\mu \mathrm{L}$ sample solution, respectively.

\subsection{Nanopore-based potentiometric biosensors}

Gold nanopores were employed by Gyurcsányi and Pretsch et al. [73] for potentiometric protein detection. They modified the inner walls of gold nanopores with biotin and monitored the change of the zero-current flux of $\mathrm{Ca}^{2+}$ ion through the modified nanopores with a $\mathrm{Ca}^{2+}$-ISE, which depends on the affinity biorecognition between biotin and avidin. The proposed method offers a novel label-free biosensing strategy for selective recognition of proteins.

Bakker et al. [74] detected surface-confined protein using an ion-channel mimetic chronopotentiometric polymeric membrane ion sensor. They covalently attached biotin to the backbone of the polymeric $\mathrm{Na}^{+}$-selective membrane so that avidin can be accumulated on the membrane surface through bioaffinity interaction, which may lead to partial blocking of the current-induced $\mathrm{Na}^{+}$-ion 
transfer across the interface between the membrane and the sample solution and subsequently a large potential drop in the so-called super-Nernstian step. Furthermore, a poly(vinyl pyrrolidone)-wetted hydrophilic track-etched polycarbonate nanopore membrane, which can reduce the effective membrane surface area, was used to place at the surface of the biotinylated ion-selective membrane to improve the detection sensitivity.

\section{Nanomaterial-based potentiometric sensors for neutral species}

SWCNTs are regarded as an excellent charge-transducing material, due to their special structure with $\pi$ electrons on the side walls and the large surface area/volume ratio. The change in electrical characteristics of SWCNTs makes them suitable for potentiometric detection. For example, Rius et al. [75] used SWCNTs as a receptor layer to develop a potentiometric sensor for detecting neutral aromatic hydrocarbon in aqueous solutions with low ionic strength. The sensing mechanism is that the adsorption of aromatic hydrocarbons onto the side walls of the CNTs through hydrophobic and $\pi-\pi$ stacking interactions could lead to the change of the interfacial double-layer capacitance between the CNTs and the sample solution and subsequently influence the potential response.

\section{Conclusions and outlook}

This review summarizes recent advances in applications of nanomaterials in potentiometric sensors. The unique, attractive properties of nanomaterials, such as excellent electrical properties and good hydrophobicities, make them ideal solid contacts in developing stable, reliable polymeric membrane solid-state ISEs.

The functionalization of nanomaterials (i.e. ionophore-modified AuNPs and CNTs) is favorable for developing stable ISEs with long operating lifetimes, due to the effective elimination of ionophore leaching from the ion-selective membrane to the sample solution.

Gold nanopores and AuNPs can be applied as alternative receptor layers to eliminate the limitations of the traditional polymeric membrane ISEs, such as the leaching of the membrane components into the sample solution and the extraction of lipophilic molecules into polymeric membrane.

Also, the incorporation of CNTs with aptamers opens up a new type of potentiometric aptasensor. Metal NPs and QDs can be used for signal transduction and amplification to develop highly sensitive potentiometric biosensors.

In conclusion, the applications of nanomaterials in potentiometric sensors are a promising research area and we expect further innovative work, such as developing other new nano-structured materials as solid contacts and applying more functionalized nanomaterials for reliable, stable, sensitive potentiometric sensors.

\section{Acknowledgements}

This work was financially supported by the Instrument Developing Project of the Chinese Academy of Sciences (YZ201161), the National Natural Science Foundation of China (20977073, 41176081) and the Taishan Scholar Program of Shandong Province (TS20081159).

\section{References}

[1] E. Bakker, E. Pretsch, Potentiometry at trace levels, Trends Anal. Chem. 20 (2001) 11-19.

[2] J. Bobacka, A. Ivaska, A. Lewenstam, Potentiometric ion sensors, Chem. Rev. 108 (2008) 329-351.

[3] T. Asefa, C.T. Duncan, K.K. Sharma, Recent advances in nanostructured chemosensors and biosensors, Analyst 134 (2009) 1980-1990.
[4] J. Bobacka, Potential stability of all-solid-state ion-selective electrodes using conducting polymers as ion-to-electron transducers, Anal. Chem. 71 (1999) 4932-4937.

[5] J. Bobacka, Conducting polymer-based solid-state ion-selective electrodes, Electroanalysis 18 (2006) 7-18.

[6] T. Lindfors, Light sensitivity and potential stability of electrically conducting polymers commonly used in solid contact ion-selective electrodes, J. Solid State Electrochem. 13 (2009) 77-89.

[7] J. Sutter, A. Radu, S. Peper, E. Bakker, E. Pretsch, Solid-contact polymeric membrane electrodes with detection limits in the subnanomolar range, Anal. Chim. Acta 523 (2004) 53-59.

[8] J. Sutter, E. Lindner, R. Gyurcsányi, E. Pretsch, A polypyrrole-based solidcontact $\mathrm{Pb}^{2+}$-selective PVC-membrane electrode with a nanomolar detection limit, Anal. Bioanal. Chem. 380 (2004) 7-14.

[9] R. De Marco, J.-P. Veder, G. Clarke, A. Nelson, K. Prince, E. Pretsch, E. Bakker, Evidence of a water layer in solid-contact polymeric ion sensors, Phys. Chem. Chem. Phys. 10 (2008) 73-76.

[10] J.-P. Veder, K. Patel, G. Clarke, E. Grygolowicz-Pawlak, D.S. Silvester, R. De Marco, E. Pretsch, E. Bakker, Synchrotron radiation/Fourier transform-infrared microspectroscopy study of undesirable water inclusions in solid-contact polymeric ion-selective electrodes, Anal. Chem. 82 (2010) 6203-6207.

[11] T. Lindfors, L. Höfler, G. Jágerszki, R.B.E. Gyurcsányi, Hyphenated FT-IRattenuated total reflection and electrochemical impedance spectroscopy technique to study the water uptake and potential stability of polymeric solid-contact ion-selective electrodes, Anal. Chem. 83 (2011) 4902-4908.

[12] B.P. Nikolskii, E.A. Materova, Solid contact in membrane ion-selective electrodes, Ion-Sel. Electrode Rev. 7 (1985) 3-39.

[13] D.M. Guldi, Fullerenes: three dimensional electron acceptor materials, Chem. Commun. (2000) 321-327.

[14] Q. Xie, E. Perez-Cordero, L. Echegoyen, Electrochemical detection of C606- and C706-: enhanced stability of fullerides in solution, J. Am. Chem. Soc. 114 (1992) 3978-3980.

[15] M. Fibbioli, K. Bandyopadhyay, S.-G. Liu, L. Echegoyen, O. Enger, F. Diederich, P. Buhlmann, E. Pretsch, Redox-active self-assembled monolayers as novel solid contacts for ion-selective electrodes, Chem. Commun. (2000) 339-340.

[16] G. Yu, J. Wang, J. McElvain, A.J. Heeger, Large-area, full-color image sensors made with semiconducting polymers, Adv. Mater. 10 (1998) 1431-1434.

[17] M. Fouskaki, N. Chaniotakis, Fullerene-based electrochemical buffer layer for ion-selective electrodes, Analyst 133 (2008) 1072-1075.

[18] C.-Z. Lai, M.A. Fierke, A. Stein, P. Bühlmann, Ion-selective electrodes with three-dimensionally ordered macroporous carbon as the solid contact, Anal. Chem. 79 (2007) 4621-4626.

[19] M.A. Fierke, C.-Z. Lai, P. Bühlmann, A. Stein, Effects of architecture and surface chemistry of three-dimensionally ordered macroporous carbon solid contacts on performance of ion-selective electrodes, Anal. Chem. 82 (2010) 680-688.

[20] C.-Z. Lai, M. Joyer, M. Fierke, N. Petkovich, A. Stein, P. Bühlmann, Subnanomolar detection limit application of ion-selective electrodes with three-dimensionally ordered macroporous (3DOM) carbon solid contacts, J. Solid State Electrochem. 13 (2009) 123-128.

[21] G.A. Crespo, S. Macho, F.X. Rius, Ion-selective electrodes using carbon nanotubes as ion-to-electron transducers, Anal. Chem. 80 (2008) 1316-1322.

[22] J. Ampurdanés, G.A. Crespo, A. Maroto, M.A. Sarmentero, P. Ballester, F.X. Rius, Determination of choline and derivatives with a solid-contact ion-selective electrode based on octaamide cavitand and carbon nanotubes, Biosens. Bioelectron. 25 (2009) 344-349.

[23] R. Hernandez, J. Riu, F.X. Rius, Determination of calcium ion in sap using carbon nanotube-based ion-selective electrodes, Analyst 135 (2010) 19791985.

[24] G. Crespo, D. Gugsa, S. Macho, F. Rius, Solid-contact pH-selective electrode using multi-walled carbon nanotubes, Anal. Bioanal. Chem. 395 (2009) 23712376.

[25] E.J. Parra, G.A. Crespo, J. Riu, A. Ruiz, F.X. Rius, Ion-selective electrodes using multi-walled carbon nanotubes as ion-to-electron transducers for the detection of perchlorate, Analyst 134 (2009) 1905-1910.

[26] A. Crespo, S. Macho, J. Bobacka, F.X. Rius, Transduction mechanism of carbon nanotubes in solid-contact ion-selective electrodes, Anal. Chem. 81 (2008) $676-681$.

[27] Z. Mousavi, J. Bobacka, A. Lewenstam, A. Ivaska, Poly(3,4-ethylenedioxythiophene) (PEDOT) doped with carbon nanotubes as ion-to-electron transducer in polymer membrane-based potassium ion-selective electrodes, J. Electroanal. Chem. 633 (2009) 246-252.

[28] F. Rius-Ruiz, A. Kisiel, A. Michalska, K. Maksymiuk, J. Riu, F. Rius, Solid-state reference electrodes based on carbon nanotubes and polyacrylate membranes, Anal. Bioanal. Chem. 399 (2011) 3613-3622.

[29] F.X. Rius-Ruiz, D. Bejarano-Nosas, P. Blondeau, J. Riu, F.X. Rius, Disposable planar reference electrode based on carbon nanotubes and polyacrylate membrane, Anal. Chem. 83 (2011) 5783-5788.

[30] J. Ping, Y. Wang, J. Wu, Y. Ying, Development of an all-solid-state potassium ion-selective electrode using graphene as the solid-contact transducer Electrochem. Commun. 13 (2011) 1529-1532.

[31] F. Li, J. Ye, M. Zhou, S. Gan, Q. Zhang, D. Han, L. Niu, All-solid-state potassiumselective electrode using graphene as the solid contact, Analyst 137 (2012) 618-623.

[32] J. Ping, Y. Wang, Y. Ying, J. Wu, Application of electrochemically reduced graphene oxide on screen-printed ion-selective electrode, Anal. Chem. 84 (2012) 3473-3479. 
[33] B. Paczosa-Bator, All-solid-state selective electrodes using carbon black, Talanta 93 (2012) 424-427.

[34] G.G. Wallace, P.R. Teasdale, G.M. Spinks, L.A.P. Kane-Maquire, Conductive Electroactive Polymers: Intelligent Materials Systems, CRC Press, Boca Raton, 2003 (pp. 121-177)

[35] T. Lindfors, H. Aarnio, A. Ivaska, Potassium-selective electrodes with stable and geometrically well-defined internal solid contact based on nanoparticles of polyaniline and plasticized poly(vinyl chloride), Anal. Chem. 79 (2007) 85718577.

[36] T. Lindfors, J.I. Szücs, F. Sundfors, R.B.E. Gyurcsányi, Polyaniline nanoparticlebased solid-contact silicone rubber ion-selective electrodes for ultratrace measurements, Anal. Chem. 82 (2010) 9425-9432.

[37] K. Saha, S.S. Agasti, C. Kim, X. Li, V.M. Rotello, Gold nanoparticles in chemical and biological sensing, Chem. Rev. 112 (2012) 2739-2779.

[38] E. Jaworska, M. Wójcik, A. Kisiel, J. Mieczkowski, A. Michalska, Gold nanoparticles solid contact for ion-selective electrodes of highly stable potential readings, Talanta 85 (2011) 1986-1989.

[39] M. Brust, M. Walker, D. Bethell, D.J. Schiffrin, R. Whyman, Synthesis of thiolderivatised gold nanoparticles in a two-phase liquid-liquid system, Chem. Commun. (1994) 801-802.

[40] J. Fink, C.J. Kiely, D. Bethell, D.J. Schiffrin, Self-organization of nanosized gold particles, Chem. Mater. 10 (1998) 922-926.

[41] M. Zhou, S. Gan, B. Cai, F. Li, W. Ma, D. Han, L. Niu, Effective solid contact for ion-selective electrodes: tetrakis(4-chlorophenyl)borate $\left(\mathrm{TB}^{-}\right)$anions doped nanocluster films, Anal. Chem. 84 (2012) 3480-3483.

[42] A. Abbaspour, A. Izadyar, Carbon nanotube composite coated platinum electrode for detection of $\mathrm{Cr}(\mathrm{III})$ in real samples, Talanta 71 (2007) 887-892.

[43] Z. Mousavi, A. Teter, A. Lewenstam, M. Maj-Zurawska, A. Ivaska, J. Bobacka, Comparison of multi-walled carbon nanotubes and poly(3-octylthiophene) as ion-to-electron transducers in all-solid-state potassium ion-selective electrodes, Electroanalysis 23 (2011) 1352-1358.

[44] J. Zhu, Y. Qin, Y. Zhang, Preparation of all solid-state potentiometric ion sensors with polymer-CNT composites, Electrochem. Commun. 11 (2009) 1684-1687.

[45] J. Zhu, X. Li, Y. Qin, Y. Zhang, Single-piece solid-contact ion-selective electrodes with polymer-carbon nanotube composites, Sens. Actuators B 148 (2010) $166-172$.

[46] K.Y. Chumbimuni-Torres, N. Rubinova, A. Radu, L.T. Kubota, E. Bakker, Solid contact potentiometric sensors for trace level measurements, Anal. Chem. 78 (2006) 1318-1322.

[47] E. Jaworska, A. Kisiel, K. Maksymiuk, A. Michalska, Lowering the resistivity of polyacrylate ion-selective membranes by platinum nanoparticles addition, Anal. Chem. 83 (2010) 438-445.

[48] G. Jagerszki, A. Grun, I. Bitter, K. Toth, R.E. Gyurcsanyi, Ionophore-gold nanoparticle conjugates for $\mathrm{Ag}^{+}$-selective sensors with nanomolar detection limit, Chem. Commun. 46 (2010) 607-609.

[49] E.J. Parra, P. Blondeau, G.A. Crespo, F.X. Rius, An effective nanostructured assembly for ion-selective electrodes. An ionophore covalently linked to carbon nanotubes for $\mathrm{Pb}^{2+}$ determination, Chem. Commun. 47 (2011) 24382440.

[50] G. Jágerszki, Á. Takács, I. Bitter, R.E. Gyurcsányi, Solid-state ion channels for potentiometric sensing, Angew. Chem. Int. Ed. 50 (2011) 1656-1659.

[51] E. Woźnica, M.M. Wójcik, M. Wojciechowski, J. Mieczkowski, E. Bulska, K. Maksymiuk, A. Michalska, Dithizone modified gold nanoparticles films for potentiometric sensing, Anal. Chem. 84 (2012) 4437-4442.

[52] R.R. Johnson, A.T.C. Johnson, M.L. Klein, Probing the structure of DNA-carbon nanotube hybrids with molecular dynamics, Nano Lett. 8 (2007) 69-75.

[53] A. Duzgun, A. Maroto, T. Mairal, C. O'Sullivan, F.X. Rius, Solid-contact potentiometric aptasensor based on aptamer functionalized carbon nanotubes for the direct determination of proteins, Analyst 135 (2010) 1037-1041.

[54] D.-H. Jung B.H. Kim, Y.K. Ko, M.S. Jung S. Jung S.Y. Lee, H.-T. Jung, Covalent attachment and hybridization of DNA oligonucleotides on patterned singlewalled carbon nanotube films, Langmuir 20 (2004) 8886-8891.
[55] G.A. Zelada-Guillén, J. Riu, A. Düzgün, F.X. Rius, Immediate detection of living bacteria at ultralow concentrations using a carbon nanotube based potentiometric aptasensor, Angew. Chem. Int. Ed. 48 (2009) 7334-7337.

[56] G.A. Zelada-Guillén, S.V. Bhosale, J. Riu, F.X. Rius, Real-time potentiometric detection of bacteria in complex samples, Anal. Chem. 82 (2010) 9254-9260.

[57] G.A. Zelada-Guillén, J.L. Sebastián-Avila, P. Blondeau, J. Riu, F.X. Rius, Label-free detection of Staphylococcus aureus in skin using real-time potentiometric biosensors based on carbon nanotubes and aptamers, Biosens. Bioelectron. 31 (2012) 226-232.

[58] A. Merkoçi, Nanoparticles-based strategies for DNA, protein and cell sensors, Biosens. Bioelectron. 26 (2010) 1164-1177.

[59] T.A. Taton, C.A. Mirkin, R.L. Letsinger, Scanometric DNA array detection with nanoparticle probes, Science 289 (2000) 1757-1760.

[60] J. Wang, R. Polsky, D. Xu, Silver-enhanced colloidal gold electrochemica stripping detection of DNA hybridization, Langmuir 17 (2001) 5739-5741.

[61] J. Wang, D. Xu, A.-N. Kawde, R. Polsky, Metal nanoparticle-based electrochemical stripping potentiometric detection of DNA hybridization, Anal. Chem. 73 (2001) 5576-5581.

[62] J. Wang, G. Liu, A. Merkoçi, Electrochemical coding technology for simultaneous detection of multiple DNA targets, J. Am. Chem. Soc. 125 (2003) 3214-3215.

63] A. Malon, T. Vigassy, E. Bakker, E. Pretsch, Potentiometry at trace levels in confined samples: ion-selective electrodes with subfemtomole detection limits, J. Am. Chem. Soc. 128 (2006) 8154-8155.

[64] N. Rubinova, K. Chumbimuni-Torres, E. Bakker, Solid-contact potentiometric polymer membrane microelectrodes for the detection of silver ions at the femtomole level, Sens. Actuators B 121 (2007) 135-141.

[65] K.Y. Chumbimuni-Torres, Z. Dai, N. Rubinova, Y. Xiang, E. Pretsch, J. Wang, E. Bakker, Potentiometric biosensing of proteins with ultrasensitive ion-selective microelectrodes and nanoparticle labels, J. Am. Chem. Soc. 128 (2006) 1367613677.

[66] A. Numnuam, K.Y. Chumbimuni-Torres, Y. Xiang, R. Bash, P. Thavarungkul, P. Kanatharana, E. Pretsch, J. Wang, E. Bakker, Potentiometric detection of DNA hybridization, J. Am. Chem. Soc. 130 (2007) 410-411.

[67] A. Numnuam, K.Y. Chumbimuni-Torres, Y. Xiang, R. Bash, P. Thavarungkul, P. Kanatharana, E. Pretsch, J. Wang, E. Bakker, Aptamer-based potentiometric measurements of proteins using ion-selective microelectrodes, Anal. Chem. 80 (2008) 707-712

[68] R. Thürer, T. Vigassy, M. Hirayama, J. Wang, E. Bakker, E. Pretsch, Potentiometric immunoassay with quantum dot labels, Anal. Chem. 79 (2007) 5107-5110.

[69] W. Ngeontae, W. Janrungroatsakul, P. Maneewattanapinyo, S. Ekgasit, W. Aeungmaitrepirom, T. Tuntulani, Novel potentiometric approach in glucose biosensor using silver nanoparticles as redox marker, Sens. Actuators B 137 (2009) 320-326

[70] I. Willner, R. Baron, B. Willner, Growing metal nanoparticles by enzymes, Adv Mater. 18 (2006) 1109-1120.

[71] K.Y. Chumbimuni-Torres, J. Wang, Nanoparticle-induced potentiometric biosensing of NADH at copper ion-selective electrodes, Analyst 134 (2009) 1614-1617.

[72] J. Wu, K.Y. Chumbimuni-Torres, M. Galik, C. Thammakhet, D.A. Haake, J. Wang, Potentiometric detection of DNA hybridization using enzyme-induced metallization and a silver ion selective electrode, Anal. Chem. 81 (2009) 10007-10012.

[73] R.E. Gyurcsanyi, T. Vigassy, E. Pretsch, Biorecognition-modulated ion fluxes through functionalized gold nanotubules as a novel label-free biosensing approach, Chem. Commun. (2003) 2560-2561.

[74] Y. Xu, E. Bakker, Ion channel mimetic chronopotentiometric polymeric membrane ion sensor for surface-confined protein detection, Langmuir 25 (2008) 568-573.

75] A.P. Washe, S. Macho, A. Crespo, F.X. Rius, Potentiometric online detection of aromatic hydrocarbons in aqueous phase using carbon nanotube-based sensors, Anal. Chem. 82 (2010) 8106-8112. 